\title{
Challenges of being a diabetic in Nepal
}

\author{
${ }^{1}$ Vivek Kattel, ${ }^{1}$ Robin Maskey, ${ }^{2}$ Poonam Lavaju , ${ }^{1}$ Rahul Taparia , ${ }^{3}$ Yamuna Agrawal \\ ${ }^{1}$ Department of Internal Medicine, ${ }^{2}$ Department of Ophthalmology, ${ }^{3}$ Department of Pathology \\ BPKIHS, Dharan
}

Diabetes mellitus burden has been escalating throughout the globe. By end of 2018 approximately 425 million adults (20-79 years) are living with diabetes and the most troublesome statistics is that $79 \%$ of adults with diabetes are living in low and middle income countries. ${ }^{1}$ The global prevalence of diabetes is $8.8 \%$ and is expected to increase every decades especially contributed by increasing prevalence from low and middle income countries. ${ }^{2}$ Nepal reports prevalence of diabetes above $8 \%$ from studies done at communities' level by different medical schools. ${ }^{3-5}$ The true burden is likely to be beyond the published data. Comprehensive quality care at low cost to patient seems to be one of the challenges in developing nation like Nepal. The point of care facilities for diabetic patients in Nepal are either less or inaccessible compared to the burden of disease. This is likely to increase the indirect cost of illness of a diabetic patient in terms of travel and accommodation which is again not easier as compared to high income country. The major gaps at current situation are first inadequate manpower in terms of primary physicians trained on diabetes at primary health care and districts hospitals, and diabetic team (diabetic physician, dietician, counselor and nurses) at zonal and tertiary hospitals. Second laboratories facilities that can monitor beyond plasma sugar level in primary care are a few in Nepal. Some of the endocrinology faculties in Nepal has taken initiative to train primary physician regarding comprehensive diabetes care however these is need of incorporation of such training in national policy level. Diabetes is not a priority disease in terms of expense of budget by health ministry in Nepal though it is public health problem that runs parallel with infectious disease. This is so because infectious disease are still priority public health issue at ministry and ministry is fighting against elimination or eradication of the infectious diseases. Private health care facilities are bridging these gaps in diabetes but still they are focused at urban areas making a rural diabetic Nepalese inaccessible. These all gaps is going to bring a diabetic patients to care point at either acute or chronic complicated status. This could be the reason for high burden of coronary artery disease, strokes and renal failure in young adults in developing nations. Diabetes with complication is going to exacerbate the cost of illness with compromised quality of life. Nepal GDP per capita income is around $\$ 1003.64$ and Nepal spends around $6 \%$ of its GDP in health. ${ }^{6}$ Literature on direct cost of illness of outpatient door (OPD) diabetes in developing countries is more than $\$ 150$ per annum. ${ }^{4}{ }^{7-9}$ If we consider global prevalence as national the direct cost of illness of an OPD based diabetic patient will account for $1.3 \%$ of Nepal GDP that is $21.6 \%$ of current health budget.2,6 Thus diabetes is high economic burden disease in Nepal.

\section{References:}

1. Christian Bommer, Esther Heesemann, Vera Sagalova, Jennifer Manne-Goehler, Rifat Atun, Till Bärnighausen, Sebastian Vollmer. The global economic burden of diabetes in adults aged 20-79 years: a cost of illness study. Lancet Diabetes Endocrinol. 2017; 5(6):423-430.

2. Global Report on Diabetes on World Diabetes Day, 2015. [Available at http://apps.who.int/iris/bitstream/ handle/10665/204871/9789241565257_eng. pdf. (Accessed on 4th November, 2018.) )] 
3. Sharma SK, Ghimire A, Radhakrishnan J, Thapa L, Shrestha NR, Paudel N et al. Prevalence of hypertension, obesity, diabetes, and metabolic syndrome in Nepal. Int J Hypertens 2011; 2011:821971.

4. Shrestha N, Lohani SP, Angdembe MR, Bhattarai K, Bhattarai J. Cost of diabetes mellitus care among patients attending selected outpatient clinics. J Nepal Med Assoc. 2013;52 (190):343-8.

5. Maskey R, Shakya DR, Sharma SK, Karki P, Lavaju P, Baranwal JK. Comparison of complications in diabetic outpatients with or without mental illness. Indian $\mathrm{J}$ Endocrinol Metab. 2013; 17(Suppl 1):S313-5.
6. Nepal GDP per Capita. CEIC, 2018. Available at https:// www.ceicdata.com/en/indicator/ nepal/gdp-per-capita (Accessed on November 5, 2018.)

7. Seuring T, Archangelidi O, Suhrcke M. The economic costs of type 2 diabetes: a global systematic review. Pharmacoeconomics 2015; 33(8):811-831.

8. Karki DB, Yadava SK, Pant S, Thusa N, Dangol E, Ghimire S. Prevalence of Sensory Neuropathy in Type 2 Diabetes Mellitus and Its Correlation with Duration of Disease. Kathmandu Univ Med J (KUMJ). 2016; 14(54):120-124.

9. Khowaja LA1, Khuwaja AK, Cosgrove P. Cost 